WSRC-TR-92-603

\title{
REMOVAL OF DEUTERIUM FROM FLOWING NITROGEN BY SAES ST $198(\mathrm{U})$
}

WSRC-TR--92-603

by $A$. Nobile

DE93 012795

Westinghouse Savannah River Company

Savannah River Site

Aiken, South Carolina 29808

Other Authors:

This paper was prepared in connection with work done under Contract No. DE-AC09-89SR18035 with the U. S. Department of Energy. By acceptance of this paper, the publisher and/or recipient acknowledges the U. S. Government's right to retain a nonexclusive, royalty-free license in and to any copyright covering this paper, along with the right to reproduce and to authorize others to reproduce all or part of the copyrighted paper. 


\section{DISCLAIMER}

This report was prepared as an account of work sponsored by an agency of the United States Government. Neither the United States Government nor any agency thereof, nor any of their employees, makes any warranty, express or implied, or assumes any legal liability or responsibility for the accuracy, completeness, or usefulness of any information, apparatus, product, or process disclosed, or represents that its use would not infringe privately owned rights. Reference herein to any specific commercial product, process, or service by trade name, trademark, manufacturer, or otherwise does not necessarily constitute or imply its endorsement, recommendation, or favoring by the United States Government or any agency thereof. The views and opinions of authors expressed herein do not necessarily state or reflect those of the United States Government or any agency thereof.

This report has been reproduced directly from the best available copy.

Available to DOE and DOE contractors from the Office of Scientific and Technical Information, P.O. Box 62, Oak Kicige, TN 37831; prices available from (615) 576-8401, FTS 626-8401.

Available to the public from the National Technical Information Service, U.S. Department of Commerce, 5285 Port Royal Rd., Springfield, VA 22161. 


\section{WESTINGHOUSE SAVANNAH RIVER COMPANY INTER-OFFICE MEMORANDUM}

WSRC-TR-92-603

December 31, 1992

TO:

T. MOTYKA, 773-A

FROM: A. NOBILE, 773-A Th for A.ebbile

\section{REMOVAL OF DEUTERIUM FROM FLOWING NITROGEN BY SAES ST 198 (U)}

\section{SUMMARY}

Testing was conducted to investigate the ability of a metal getter, SAES St 198, to remove $D_{2}$ from flowing nitrogen. This getter is being considered for applications involving removal of tritium at low concentrations from glovebox atmospheres and inert or nitrogen process streams. This document reports results from tests

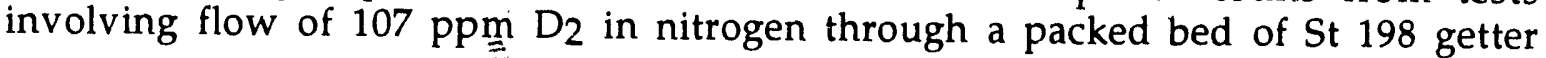
granules $\left(1.02 \mathrm{~mm}\right.$ average diam.) at a gas flow rate of $400 \mathrm{std} . \mathrm{cm}^{3} \cdot \mathrm{min}^{-1}$. The first of two tests (Run 1) was conducted at a temperature of $350{ }^{\circ} \mathrm{C}$, and the getter reactor contained 9.7 grams of getter. The second test (Run 2) was at $250{ }^{\circ} \mathrm{C}$, and the reactor contained 5.1 grams of getter. The tests involved continuous flow of the $\mathrm{D}_{2} / \mathrm{N}_{2}$ mixture into the getter bed for several days, during which the inlet and outlet streams were analyzed for $\mathrm{D}_{2}$ by mass spectrometry at $12 \mathrm{~h}$ intervals. For both runs, testing continued until nearly complete breakthrough of deuterium was observed. During Run 1 no $D_{2}$ was detected in the getter bed exit stream for $122 \mathrm{~h}$, and during Run 2, no D2 was detected in the exit gas for $84 \mathrm{~h}$. The lower detection limit of the mass spectrometer was $0.5 \mathrm{ppm}$, so the decontamination factor (DF) for both runs was at least 200 . Successful $D_{2}$ removal from nitrogen in the tests indicates that further investigation of the stripping ability of St 198 with tritium should be pursued.
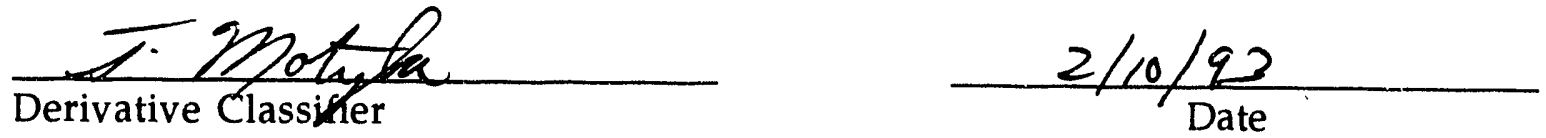
T. MOTYKA

WSRC-TR-92-603

Page 2

December 31, 1992

\section{BACKGROUND}

Current glovebox tritium cleanup systems rely on catalytic tritium oxidation and subsequent tritiated water removal on molecular sieve beds. While this technique is robust and widely used, it undesirably creates tritiated water which must be reprocessed, and is highly radiotoxic. A glovebox cleanup system based on tritium removal from glovebox atmospheres by reaction with a metal getter would not form tritiated water, and would offer the potential of direct recovery of elemental tritium. Such a cleanup system would be safer to operate, and would generate less tritiated waste.

A metal getter having the nominal composition $\mathrm{Zr}_{2} \mathrm{Fe}$, which is produced and sold by SAES Cetters under the trade name St 198, has the unique property of being reactive with hydrogen isotopes, oxygen, water, and other glovebox impurity gases, while remaining relatively unreactive toward nitrogen. Additionally, the material is commercially available in the form of pressed pellets that can be used in a packed bed reactor with minimal gas pressure drop. SRTC is therefore considering these getters for applications involving tritium removal from glovebox atmospheres and inert gas process streams with low tritium concentrations. A study aimed at characterizing the deuterium absorption and material phase characteristics of St 198 has been conducted, and the results from this study have been presented in another report (1).

A glovebox tritium cleanup system based in the use of St 198 has already been developed and built by the Ontario Hydro Research Division (2), and in fact, in a collaborative effort between SAES Getters and Ontario Hydro Research, a tritium cleanup system using St 198 has been designed for commercial sale. Although tritium tests on the Ontario Hydro tritium cleanup system $(2,3)$ demonstrated successful removal of tritium from the glovebox atmosphere for tritium concentrations less than $1 \mathrm{mCi} \cdot \mathrm{m}^{-3}$, at higher concentrations, tritium was observed in the exit stream of the St 198 metal getter bed.

While this work has demonstrated the usefulness of St 198 for process and glovebox tritium cleanup systems, the problem of tritium breakthrough at higher tritium concentrations will have to be solved before this technology can be widely used. The Ontario Hydro metal getter bed design appears to be far from optimized, and it is probable that an improved design will solve the tritium breakthrough problem.

The goal of the program underway at SRTC is not only to optimize the metal getter bed design, but to have on hand the ability to design metal getter beds for specific applications as they arise. There are a number of applications which have already been proposed for the metal getter stripping technology, and these include:

- Glovebox cleanup systems for use in the Materials Test Facility (MTF).

- Removal of tritium contamination from ${ }^{3} \mathrm{He}$ for commercial sales. 
T. MOTYKA

WSRC-TR-92-603

Page 3

December 31, 1992

- Cleanup of tritium contamination from argon which is exhausted from vacuum pumps used in the Life Storage Program in the MTF.

Other applications are likely to arise as time progresses.

To achieve the objectives of the program, work has been concentrated in the following four main areas to produce information which when combined will produce the desired end result. These three main areas are as follows:

- Extensive characterization of the deuterium absorption and material phase characteristics of the candidate getter material.

- Tests involving flow of $\mathrm{D}_{2}$-containing nitrogen through a metal getter bed to simulate the flow conditions in a metal getter tritium cleanup system.

- Development of a computer design code to be used as a tool to design metal getter reactors.

- Installation of a demonstration unit in the SRS Tritium Facility.

Results from the first two areas of the program are intended to supply the information needed for development of the computer design code. Characterization of the candidate material (St 198) is complete, and the results from this part of the program have been reported (1). Other materials can be characterized on an asneeded basis. This memorandum reports results from the second part of the program. A computer design code has been developed and demonstrated, and a future report will contain the results from this part of the program.

Results reported and discussed in this memorandum were obtained from tests conducted at Los Alamos National Laivoratory (LANL) on an apparatus specifically built for studying $\mathrm{D}_{2}$ and $\mathrm{T}_{2}$ removal by metal getters from flowing nitrogen or $\mathrm{i}^{-}$ert gas streams. Tests with $D_{2}$ in nitrogen were conducted at temperatures of 250 and $350^{\circ} \mathrm{C}$. $\mathrm{D}_{2}$ was successfully removed at both temperatures. Material characterization of getter samples from the LANL tests have been performed at SRS by Clanton Mosley. Some preliminary aspects of these characterization results will be discussed, but a more detailed accounting of the characterization work will be provided in a future report.

\section{EXPERIMENTAL}

Flow tests were conducted in an all-metal system shown schematically in Figure 1. Although the system was designed for continuous gas recirculation, tests reported in this memorandum were conducted in a once-through mode where gas was supplied from cylinders and was discharged to and air hood after passing through the metal getter sample bed. Gas flow was introduced by two flow controllers adjacent to the 
T. MOTYKA

WSRC-TR-92-603

Page 4

December 31, 1992

metal bellows pump, and followed the path through valves $5,9,11,13,12,14,2$, and to the air hood. The $107 \mathrm{ppm}$ mixture was created by blending a mixture of $1000 \mathrm{ppm}$ $\mathrm{D}_{2}$ in nitrogen with pure nitrogen so that the total flow rate was $400 \mathrm{std} . \mathrm{cm}^{3} \cdot \mathrm{min}^{-1}$ (sccm). An MKS control valve and pressure controller regulated the pressure in the system to 740 torr.

The sample metal getter bed consisted of a stainless steel sleeve with $5 \mathrm{~mm}$ inconel frits (16 mm diam) on each end. The sleeve was wrapped with zirconia cloth, that was in turn wrapped with a nichrome wire heater. Each frit was drilled at its center and contained a thermowell which contained a type $\mathrm{K}$ thermocouple. The getter bed temperature was controlled by a temperature controller which took its signal from the thermocouple at the exit end of the getter bed. The getter bed was $3.2 \mathrm{~cm}$ long $x$ $1.2 \mathrm{~cm}$ diam. In Run 1 which was conducted at $350^{\circ} \mathrm{C}, 9.7$ grams of getter were used, and this completely filled the getter bed volume. In Run 2 which was conducted at $250{ }^{\circ} \mathrm{C}, 5.1$ grams of getter were used, and this quantity of material filled only about $53 \%$ of the getter bed volume. The getter bed was held in a vertical position and gas flowed from top to bottom, so no fluidization of the bed occurred during either run.

St 198 metal getter is purchased as rigid $4 \mathrm{~mm}$ long $\times 6 \mathrm{~mm}$ diam. rigid pellets that are pressed from powder. These pellets were crushed in a mortar and pestle and sieved to yield particles having diameters in the range 850 to $1180 \mathrm{~mm}$, which yields an average particle diameter of $1015 \mathrm{~mm}$. The ratio of reactor diameter to particle diameter of 12 was sufficiently large to neglect wall channeling effects. After placing the sample in the getter bed, the sample was activated by heating to $350{ }^{\circ} \mathrm{C}$ under flowing nitrogen $(400 \mathrm{sccm})$ for $4 \mathrm{~h}$. After introducing the $107 \mathrm{ppm} \mathrm{D} 2 / \mathrm{N}_{2}$ mixture, samples from the bed inlet and outlet streams were analyzed for $\mathrm{D}_{2}$ with a mass spectrometer. Analysis of the inlet and outlet gas continued until breakthrough of D2 was nearly complete.

\section{RESULTS}

Data consisting of the inlet and outlet stream $\mathrm{D}_{2}$ concentration for Run 1 are shown in Figure 2. The data points represent the measured values, and the solid curve represents the expected breakthrough curve that was calculated from the computer model. No $D_{2}$ was detected in the getter bed exit stream for $122 \mathrm{~h}$, after which breakthrough of $\mathrm{D}_{2}$ was observed. The exit $\mathrm{D}_{2}$ concentration increased steadily between 130 and about $180 \mathrm{~h}$, but began to increase at a slower rate at time longer than about $180 \mathrm{~h}$. Since the lower detection limit on the mass spectrometer was about 0.5 ppm D2, it can be stated that the DF of the getter bed is at least 200. D2 breakthrough occurred slightly later than predicted by the model, and the slope of the measured breakthrough curve is less than the model curve.

Inlet and outlet stream $\mathrm{D}_{2}$ concentrations for Run 2 are shown in Figure 3 . No $\mathrm{D}_{2}$ was detected in the exit stream until $96 \mathrm{~h}$ when breakthrough was detected. The deuterium concentration increased continuously until it reached about $100 \mathrm{ppm}$. The exit stream concentration remained stable at about $100 \mathrm{ppm}$ for an additional 30 
$\mathrm{h}$ when the test was terminated. Unlike the run at $350{ }^{\circ} \mathrm{C}, \mathrm{D}_{2}$ breakthrough was detected significantly earlier than predicted by the model.

X-ray diffraction patterns of samples from Runs 1 and 2 indicated that at the higher temperature run (Run 1) there was significant disproportionation of the getter material to form $\mathrm{ZrD}_{2}$. In the lower temperature run, little or no $\mathrm{ZrC}_{L}$ was detected. The disproportionation reaction has been discussed in a previous document (1) which discusses the characterization work on St 198 done at SRTC.

\section{DISCUSSION}

The above results indicate that St 198 is effective for removing $D_{2}$ from nitrogen at 250 and $350{ }^{\circ} \mathrm{C}$. It can be conservatively stated that a DF of at least 200 was the case in both runs. Most likely, the DF is significantly higher, but since the mass spectrometer used had a lower detection limit of $0.5 \mathrm{ppm}$, it cannot be stated with certainty that the DF is higher. When working with $D_{2}$, one is limited by the analytical detection limit. Tests must be run with tritium to demonstrate more realistically the DF. In such tests, an ion chamber that has much lower detection limit will be more appropriate. The deuterium results indicate that tritium removal is probably feasible, and is worthy of further investigation with tritium.

In the two runs, deviations between the model and the experimental data were seen. Detailed discussion of the model will be described in a later document, but for the purpose of this discussion, it can be stated that the model consists of solution of the governing differential equations for a packed bed which absorbs a minor component from a flowing gas stream. Deviations between the model and experimental data can be attributed to two factors: 1) the getter absorption kinetics which are operative in the flow experiments are rot in agreement with the kinetics used in the model, which were measured under somewhat different conditions, and 2) disproportionation of the getter to form $\mathrm{ZrD}_{2}$ increases the actual capacity of the material.

X-ray diffraction results indicated that there was significant disproportionation and formation of $\mathrm{ZrD}_{2}$ in Run 1 . This disproportionation causes an increase in the material capacity, and would be consistent with a delay in $\mathrm{D}_{2}$ breakthrough. Slower absorption kinetics in the flowing experiments would cause broadening of the breakthrough curve, and may partially account for the fact that the slope of the actual breakthrough curve is less than predicted by the model. Disproportionation also continues after breakthrough, so this could also change the shape of the breakthrough curve. Thus, at $350{ }^{\circ} \mathrm{C}$, both absorption rate effects as well as disproportionation effects are probably responsible for the deviation between the model and the experiment. Future work will focus on accounting for these effects in the model in attempt to achieve agreement between the model and the data. 
T. MOTYKA

WSRC-TR-92-603

Page 6

December 31, 1992

At $250^{\circ} \mathrm{C}$ (Run 2) $\mathrm{D}_{2}$ breakthrough was observed well before expected from the model calculations. X-ray diffraction indicates only slight disproportionation at 250 ${ }^{\circ} \mathrm{C}$, so disproportionation does not play a role in determining the breakthrough curve at this temperature. It is more likely that deuterium absorption kinetics in the flow tests deviated from the absorption kinetics used in the model. Slower absorption kinetics tend to broaden the breakthrough curve, so this would explain the broader curve and earlier $\mathrm{D}_{2}$ breakthrough. Future work will attempt to adjust the kinetics to improve the agreement between the data and the model. The Run 2 breakthrough curve reached a constant concentration at $100 \mathrm{ppm}$, or about $7 \mathrm{ppm}$ below the inlet concentration. There apparently was still some deuterium consumption from the gas stream which remained relatively constant for about $50 \mathrm{~h}$. This is probably a result of some disproportionation of the getter occurring and consuming deuterium from the gas phase. Slow deuterium consumption irom the flowing gas stream would result in a relatively constant outlet stream $D_{2}$ concentration. The extent of the deviation between the outlet $\mathrm{D}_{2}$ concentration and the inlet $\mathrm{D}_{2}$ concentration would be proportional to the rate of $\mathrm{D}_{2}$ consumption by the disproportionation reaction.

The results indicate that operation at a temperature anywhere between 250 and 350 ${ }^{\circ} \mathrm{C}$ would be adequate for a tritium stripping application. However, as long as the tritium loading of the getter is relatively low, disproportionation effects will be small, and it would be preferable to operate at higher temperature to avoid tritium absorption rate inhibition by impurities.

\section{CONCLUSION}

Tests to determine the ability of SAES St 198 to remove $\mathrm{D}_{2}$ from a flowing nitrogen stream indicated that at temperatures of 250 and $350{ }^{\circ} \mathrm{C}$, DF values of at least 200 and likely higher are the case. The successful removal of $D_{2}$ from nitrogen indicates that it is worth proceeding to develop an application which demonstrates tritium removal from nitrogen or an inert gas using St 198. Even though some disproportionation of St 198 occurs at $350^{\circ} \mathrm{C}$, this should not be a problem in a tritium application, since the actual hydrogen isotope loading will be much lower than was the case in these tests. It is probably preferable to operate near $350^{\circ} \mathrm{C}$, since the getter performance will be less sensitive to impurities at the higher temperature.

\section{REFERENCES}

1. Nobile, A., Mosley, W. C., Holder, J. S., and Brooks, K. N., WSRC-TR-92-557.

2. Shmayda, W. T., Kherani, N. P., Wallace, B., and Mazza, F., Fusion Technology Vol. 21, 616 (1992).

3. Kherani, N. P., Shmayda, W. T., and Jalbert, R. A., Proceedings of the 12th Symposium on Fusion Engineering, Monterey, CA., October 12-16, 1987, I. E. Conf. No. 11702. 
T. MOTYKA

WSRC-TR-92-603

Page 7

December 31, 1992

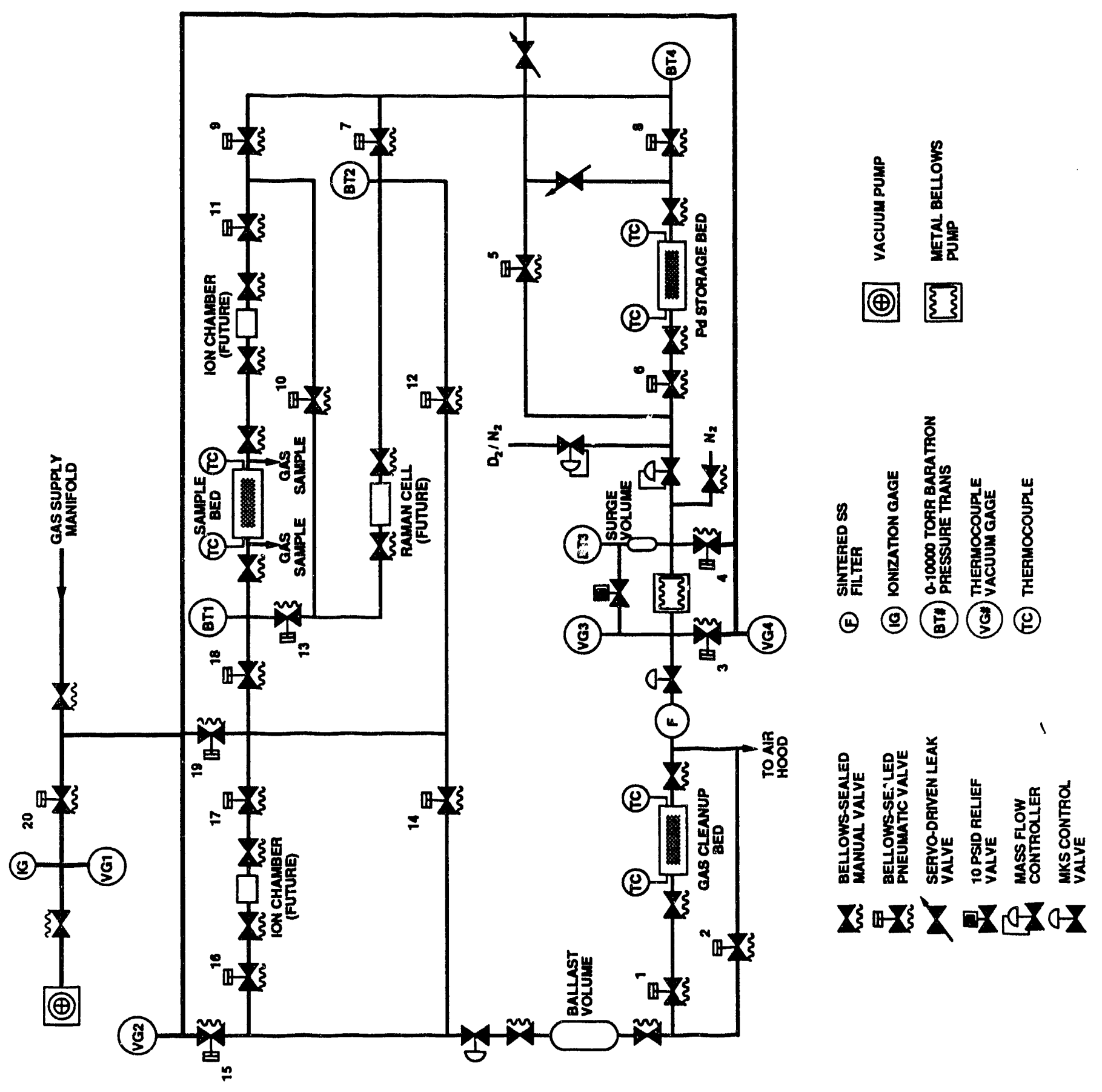

Figure 1. Test apparatus. 
WSRC-TR-92-603

Page 8

December 31, 1992

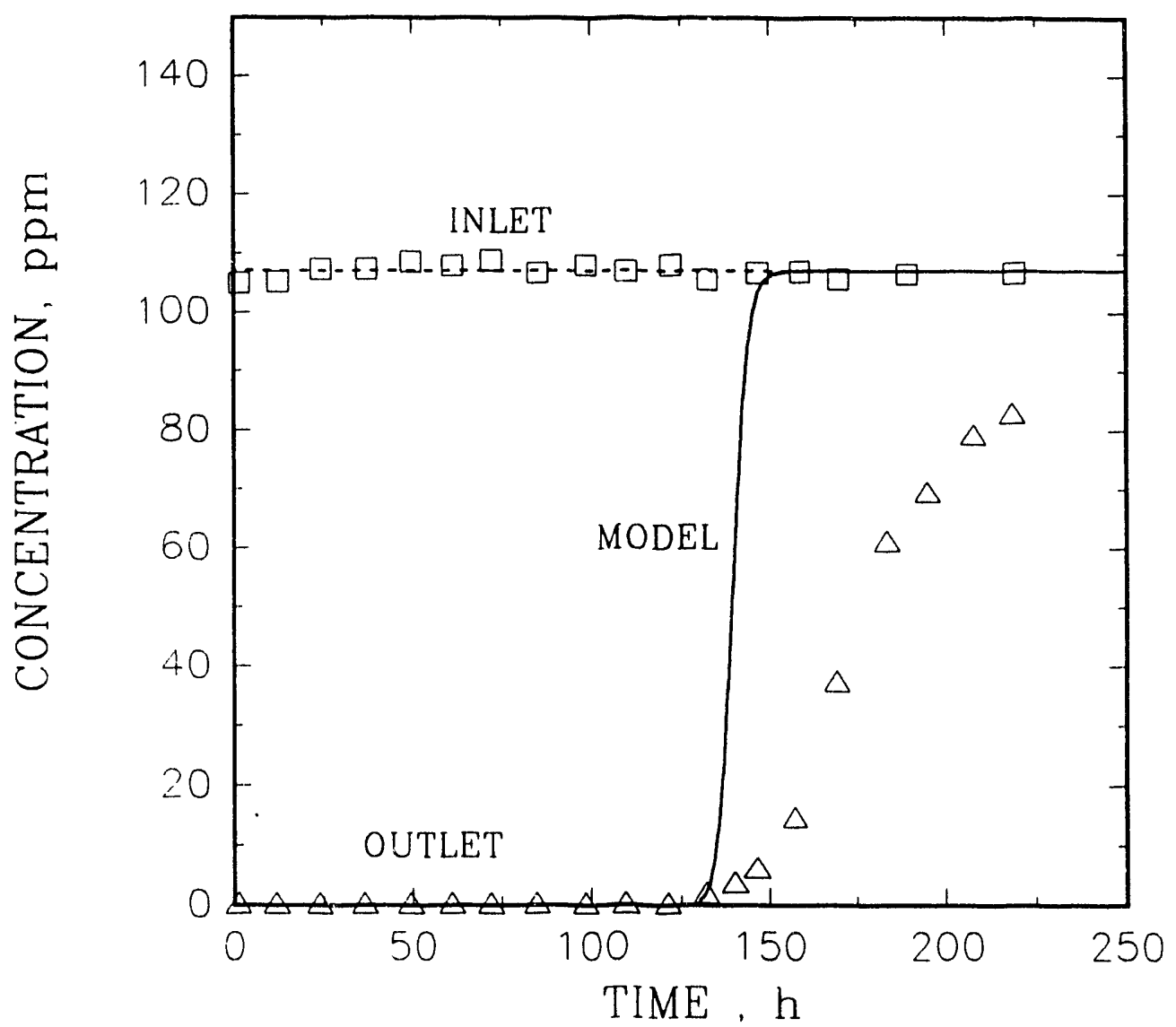

Figure 2. Results from Run 1 ; temperature $-350^{\circ} \mathrm{C}$, flow rate $-400 \mathrm{sccm}$, sample quantity $-9.7 \mathrm{~g}$ 
T. MOTYKA

WSRC-TR-92-603

Page 9

December 31, 1992

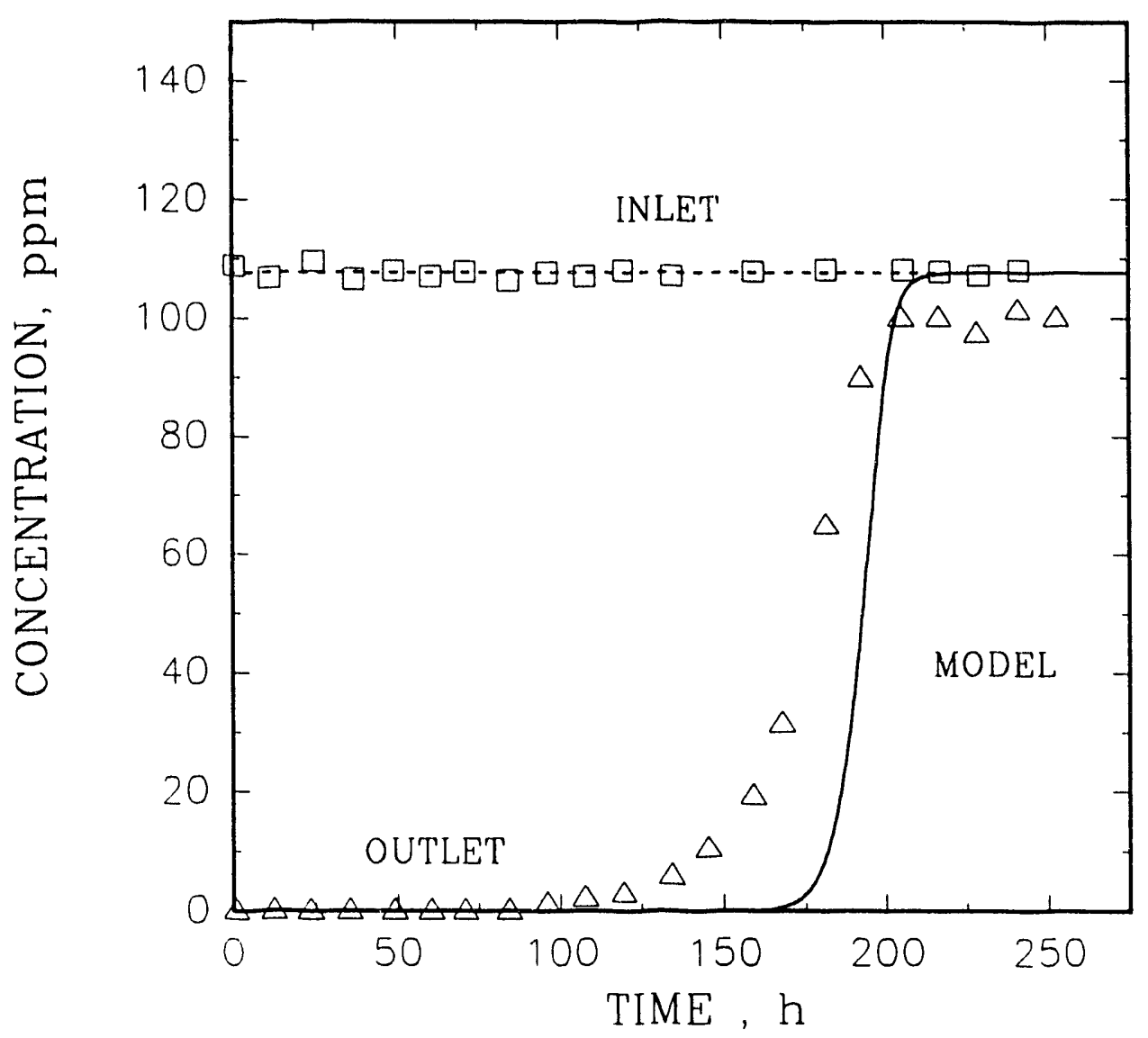

Figure 3. Results from Run 2; temperature $-250^{\circ} \mathrm{C}$, flow rate $-400 \mathrm{sccm}$, sample quantity $-5.1 \mathrm{~g}$ 

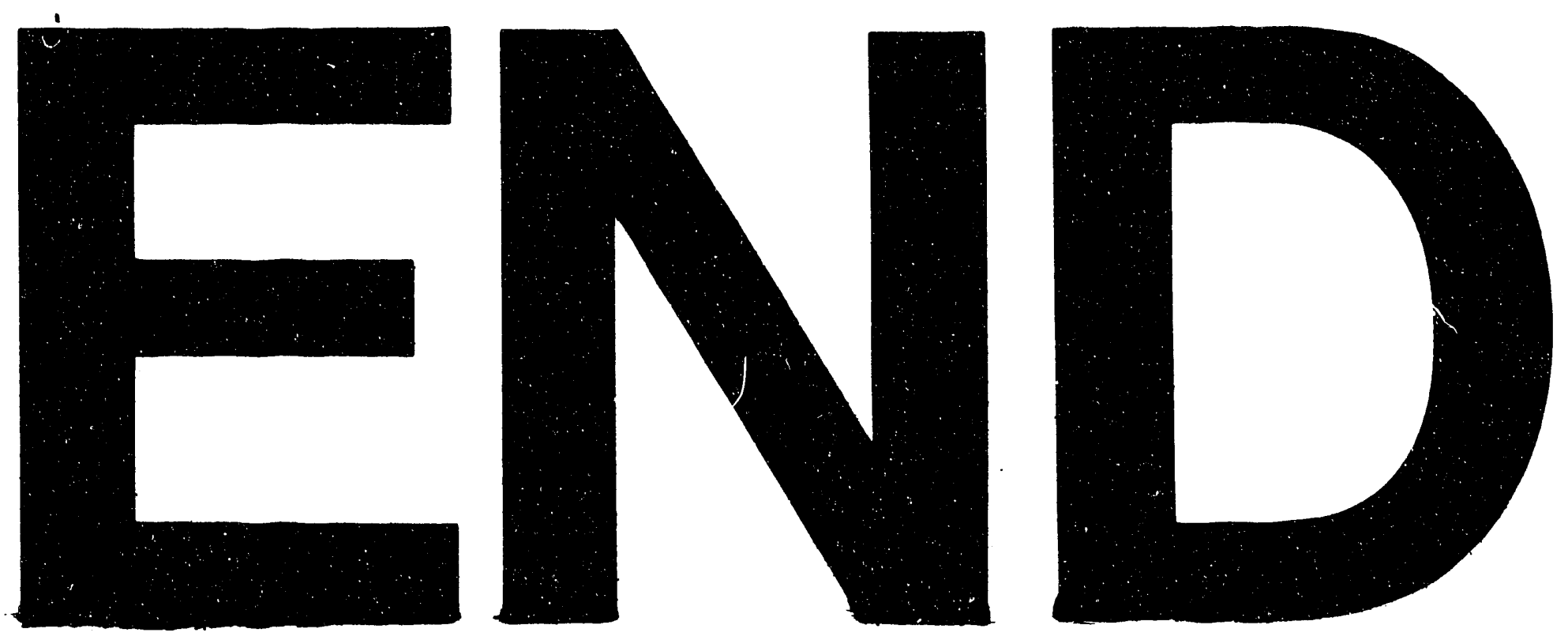

$x$
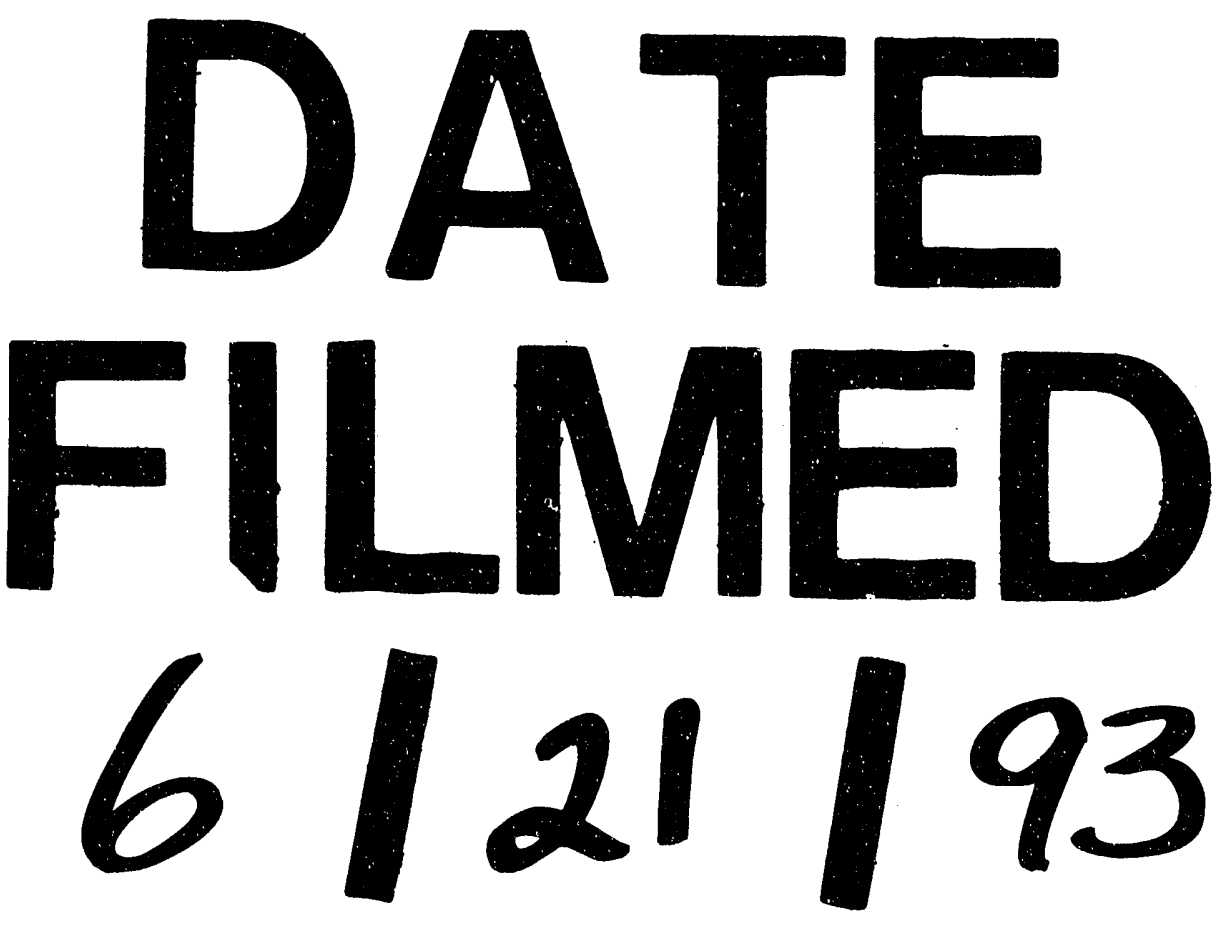